\title{
Reflections on the Challenges of Writing a (Pre-)History of the "Polarized" Present
}

\author{
Thomas Zimmer
}

Polarization is everywhere. It is, according to the Pew Research Center, "a defining feature of American politics today." Elected officials, journalists, and political pundits seem to agree that it is a severe problem in urgent need of fixing, maybe even the root of all evil that plagues the United States, from dysfunction in Congress to the decay of social and cultural norms. ${ }^{1}$ Many historians, too, have embraced the concept of polarization for its explanatory power: It has emerged as the closest thing to a master narrative for recent American history. In this interpretation, the "liberal consensus" that had dominated mid-twentieth-century American politics and intellectual life-the widely shared acceptance of New Deal philosophy and broad agreement on the desirable contours of society and the pursuit of certain kinds of public good-gave way after the 1960s to an age of heightened tension, dividing Americans into two camps that since then have regarded each other with deepening distrust. ${ }^{2}$ Yet too few historians have reflected on the limits and potential pitfalls of using polarization as a governing historical paradigm. It is high time, therefore, to pause to consider the larger implications of approaching the past through the prism of polarization.

Long before historians started adopting the term, polarization had been theorized by political scientists, who first warned of its effects on the body politic in the mid-1980s. ${ }^{3}$ Scholars have usually focused on political or partisan polarization, defining it, in simple terms, as a widening gap between the two major parties, resulting from Democrats becoming more liberal and Republicans becoming more conservative. ${ }^{4}$ No one disputes that polarization is particularly pronounced in Congress, where it has increased basically every year since at least the late 1970s. There is little consensus, however, regarding the question of whether or not the general electorate has also become more polarized. Two camps have long dominated this particular political science debate. One, led by Alan Abramowitz, argues that the policy attitudes of

\footnotetext{
${ }^{1}$ Pew Research Center, "Political Polarization," https://www.pewresearch.org/topics/political-polarization/2019/ (accessed Oct. 16, 2019). See also Politico, "How to Fix: Polarization," https://www.politico.com/interactives/ 2019/how-to-fix-politics-in-america/polarization/ (accessed Oct. 16, 2019). For a selection of book publications by journalists and political analysts who lament polarization see, for instance, Darrell M. West, Divided Politics, Divided Nation: Hyperconflict in the Trump Era (Washington, DC, 2019); Steve Kornacki, The Red and the Blue: The 1990s and the Birth of Political Tribalism (New York, 2018); John A. Lawrence, The Class of '74: Congress after Watergate and the Roots of Partisanship (Baltimore, 2018).

${ }^{2}$ The classic contemporaneous account is John Higham, "The Cult of the 'American Consensus': Homogenizing Our History," Commentary 27 (Jan. 1959): 93-100. For an influential definition of the "liberal consensus," see Godfrey Hodgson, America in Our Time (New York, 1978), 67-98. For a more recent examination of the liberal order see Jefferson Cowie, The Great Exception: The New Deal and the Limits of American Politics (Princeton, NJ, 2017).

${ }^{3}$ Keith T. Poole and Howard Rosenthal, "The Polarization of American Politics," Journal of Politics 46, no. 4 (1984): 1061-79.

${ }^{4}$ A useful overview over the state of polarization research in the political sciences is provided by Lilliana Mason, Uncivil Agreement: How Politics Became Our Identity (Chicago, 2018), 76-7; Sam Rosenfeld, The Polarizers: Postwar Architects of Our Partisan Era (Chicago, 2018), 287-94; Nolan McCarty, Polarization: What Everyone Needs to Know (New York, 2019), ch. 2.

(c) The Author(s) 2019. Published by Cambridge University Press. This is an Open Access article, distributed under the terms of the Creative Commons Attribution licence (http://creativecommons.org/licenses/by/4.0/), which permits unrestricted re-use, distribution, and reproduction in any medium, provided the original work is properly cited.
} 
regular voters have indeed become more extreme. The other, headed by Morris Fiorina, contends that the increasing gap between the parties is actually the result not of ideological polarization, but of partisan sorting: liberals have uniformly joined the Democratic Party, while conservatives have united under the GOP's banner. ${ }^{5}$ Most recently, Liliana Mason has offered a way to transcend these well-dug trenches. She focuses on the formation and effects of group identities and on what she calls "social polarization." Mason diagnoses the alignment of ideological, religious, racial, and gender identities along partisan lines-a development that goes well beyond the type of sorting the Fiorina camp is describing, as it creates "mega-identities" and increases the social distance between the parties. Contrary to what Abramowitz argues, the strengthening identification of voters with either a conservative Republican Party or a liberal Democratic Party is, in this analysis, not necessarily rooted in ideological disagreements. It does, however, shape electoral behavior and, at least in the medium-term, policy attitudes; and the tribal partisanship that follows from social polarization has a pervasive influence on all aspects of American democracy. ${ }^{6}$

Historians have been slower to employ the term, but by the 2010s a whole genre of books seeking to explain, in Andrew Hartman's words, the phenomenon of "persistent and worsening polarization" has flourished. ${ }^{7}$ Some of these genealogies of polarization have answered the question of how Americans have become so divided by pointing to the collapse of the political center-either because of the slow death of moderate Republicanism and the "virtual extinction" of moderate voices in the GOP, or, somewhat less convincingly, because of liberal abandonment of moderate positions. ${ }^{8}$ Other books, by contrast, have sought the origins of contemporary polarization in specific hot-button issues, tracing, for example, the long-lasting, polarizing effects of debates over bilingual and sex education in California during the 1960s and 1970s or the battle over women's rights. ${ }^{9}$ Yet all these scholarly efforts share as their starting point the idea that by the end of the Obama era, "the nation was more divided than ever" and that pre-histories are needed to understand the "increasingly polarized condition of American politics."10

This quest to produce a genealogy of the polarized present in many respects culminated in early 2019 with the publication of Kevin Kruse's and Julian Zelizer's Fault Lines: A History of the United States since 1974. Starting from the assumption of a deeply polarized American polity, the authors inquire how we got from Watergate to where we are today. They identify four areas of gradually deepening division: economic inequality, political partisanship, and questions of identity relating to race, as well as gender and sexuality. Fault Lines stands out not only because the authors are prominent public intellectuals, but also because Kruse and Zelizer explicitly make polarization the framework for their overview of U.S. history since the 1970s-thus elevating it to the status of a master narrative. ${ }^{11}$

\footnotetext{
${ }^{5}$ For the contours of this debate, see Alan I. Abramowitz and Kyle L. Saunders, "Is Polarization a Myth?" Journal of Politics 70, no. 2 (2008): 542-55; Morris P. Fiorina, Samuel J. Abrams, and Jeremy C. Pope, "Polarization in the American Public: Misconceptions and Misreadings," Journal of Politics 70, no. 2 (2008): 556-60; Morris P. Fiorina, Unstable Majorities: Polarization, Party Sorting \& Political Stalemate (Redwood City, CA, 2017); Alan I. Abramovitz, The Great Alignment: Race, Party Transformation, and The Rise of Donald Trump (New Haven, CT, 2018).

${ }^{6}$ Mason, Uncivil Agreement.

${ }^{7}$ Andrew Hartman, A War for the Soul of America: A History of the Culture Wars, 2nd ed. (Chicago, 2019$), 286$.

${ }^{8}$ Geoffrey Kabaservice, Rule and Ruin: The Downfall of Moderation and the Destruction of the Republican Party, from Eisenhower to the Tea Party (New York, 2012), xix; Jeffrey Bloodworth, Losing the Center: The Decline of American Liberalism, 1968-1992 (Lexington, KY, 2013).

${ }^{9}$ Natalia M. Petrzela, Classroom Wars: Language, Sex, and the Making of Modern Political Culture, (New York, 2015); Marjorie J. Spruill, Divided We Stand: The Battle over Women's Rights and Family Values That Polarized American Politics (New York, 2017).

${ }^{10}$ Spruill, Divided We Stand, 343; Kabaservice, Rule and Ruin, 364.

${ }^{11}$ Kevin M. Kruse and Julian E. Zelizer, Fault Lines: A History of the United States since 1974 (New York, 2019).
} 
Historians, in short, have found the polarization paradigm useful, because it provides an overarching theme and terminology for interpreting seemingly disparate developments in politics, society, and culture since the demise of the mid-twentieth-century liberal order. Conflicts over education policy or women's rights and fights over Supreme Court nominations no longer appear as isolated phenomena, but strands that can be woven together into a grand tale of American disunity since the 1960s. Furthermore, such histories serve as investigations into the origins of what is widely considered the most pressing issue in American politics today, and therefore hope to make direct interventions into ongoing societal debates. Most authors (or publishers) surely relish the heightened public attention that often follows. In this way, the tale of polarization turns into an explosive "history of now." ${ }^{12}$

But the framework also has blind spots and potential pitfalls that deserve historians' careful attention. Widely used, polarization nevertheless remains under-theorized in recent historical studies, both as an empirical reality as well as an analytical concept. Scholars have walked into what we might call the common sense trap, no longer treating the idea of polarization with necessary skepticism and analytical rigor. Historians almost never spend much time defining what they mean by "polarization"; it is assumed to be self-explanatory. As a result, the term often lacks conceptual clarity, being simply deployed near-synonymously with disunity and dysfunction. Most historians, moreover, are not overly concerned with delineating the exact scope of polarization at any given moment. Kruse and Zelizer, for instance, do not consistently separate the idea of a widespread change of substantive opinions on one hand and the partisan sorting of ideological views on the other. And little do the authors of Fault Lines distinguish between political elites and the mass electorate. This, in particular, strikes me as a missed opportunity: The question of how elites and regular voters have interacted is one of the more pressing questions among political scientists, and historians seem better equipped to tackle it, as they are more adept at qualifying subtle developments in the broader political and cultural discourses over time rather than focusing on quantifiable shifts based on opinion polls and statistical data.

The question of change over time points to one of the more surprising deficiencies of the historical engagement with the polarization thesis. While everyone, historians and political scientists alike, agrees that the problem started in the 1970s, the dynamics of polarization since then remain hazy. Are we to imagine this as a continually progressing process-or one that has unfolded rather discontinuously, in fits and starts, with periods of relative quiet, maybe even decreasing discord, mixed in? Historical analyses would benefit from reflecting about matters of periodization more explicitly, particularly since these are precisely the questions to which political science approaches are unlikely to provide satisfactory answers.

Paying closer attention to conceptual clarity and questions of scope as well as periodization would go a long way toward providing a clearer history of polarization. But we also might consider the larger historiographical implications of examining the past through the lens of polarization-of history as polarization, so to speak. Here I would like to offer three observations plus the outline of a tentative research agenda. First, the paradigm requires, or at least implies, a development in which both sides of the political spectrum adopt increasingly extreme positions. There is little doubt, however, that over the past fifty years, the widening gap between the parties has been caused mainly by Republicans in Congress and the GOP base moving sharply to the right and becoming much more conservative. This dynamic has been identified most clearly by media historians who study the rise of the right-wing media ecosystem since the

\footnotetext{
${ }^{12}$ I first came across the term "history of now" when Patrick Iber announced he was teaching a course of that name at the University of Wisconsin-Madison in the 2019 fall semester, see https://patrickiber.org/2019/04/11/syl labus-fall-2019-history-of-now-advanced-seminar/.
} 
late 1980s. ${ }^{13}$ Consequently, Nicole Hemmer, in her study of conservative "media activists," does not use the term polarization, but paints a picture of an ongoing radicalization of the (new) right. ${ }^{14}$ By contrast, if the divided American media landscape is portrayed through the polarization lens instead, the endeavor easily turns into a search for equivalence where there is none to be found. ${ }^{15}$ It gives the impression that both sides have radicalized to some extent (and that is, at the very least, also what the use of the term in the broader public discourse implies).

Jill Lepore's grand retelling of U.S. history since the founding offers a case in point. Lepore relies heavily on the polarization trope for her interpretation of post-1960s America. When talking about the media, the author assures us that "the rise of cable news accelerated the polarization" of both Congress and the electorate. ${ }^{16}$ The late twentieth century, according to Lepore, witnessed the emergence of partisan news media on both sides, to the point where agreement, even regarding factual reality, became impossible. The devastating result: "mutually assured epistemological destruction." ${ }^{\prime 7}$ The metaphor is striking-but it is not supported by the evidence presented in the book and hinges on the questionable characterization of Fox News and MSNBC as equally partisan. When Lepore gives a detailed account of Rush Limbaugh's outsized influence on conservative politics or the machinations of conspiracy theorist Alex Jones, it becomes clear that there are simply no equal counterparts on the left. ${ }^{18}$ And yet, the narrative of polarization indicates that there should be, and encourages the search for (false) equivalence.

Second, the polarization thesis has strongly teleological connotations. Such a perspective tends to accentuate whatever and whoever has acted as a driving force for disunity while downplaying countervailing developments, agreements, and moments of openness that are not easily integrated into the framework of deepening division. As some scholars have pointed out, in important ways recent history can be characterized by widespread consensus on many issues that have transcended partisan or ideological boundaries-from the new intellectual orthodoxy focused on individuals, fluid identities, contingency, and flexibility traced by Daniel T. Rodgers to the broad support across the ideological spectrum for "law and order" policies that preserve the existing racial, political, social, and economic hierarchies emphasized by Matthew Lassiter. Bipartisanship is not dead, Lassiter reminds us, but thinking in terms of an "artificial red-blue binary" obscures places where it lurks. ${ }^{19}$

Beyond considering the possibility of persisting structural consensus, historians might even reconsider some of those supposed wedge issues that have provided so much fodder for the polarization argument. It is often assumed, for instance, that the country polarized around the question of abortion, but in fact few people support either full legalization or a complete ban under any circumstances, and public opinion actually seems to have been clustered pretty

\footnotetext{
${ }^{13}$ Nicole Hemmer, Messengers of the Right: Conservative Media and the Transformation of American Politics (Philadelphia, 2016); Bruce J. Schulman and Julian E. Zelizer, eds., Media Nation: The Political History of News in Modern America (Philadelphia, 2017); Brian Rosenwald, Talk Radio's America: How an Industry Took Over a Political Party that Took Over the United States (Cambridge, MA, 2019).

${ }^{14}$ Hemmer, Messengers.

${ }^{15}$ The polarization framework might, if employed carefully, allow for some asymmetry between left and right. On the idea of "asymmetrical polarization," see Matt Grossman and David A. Hopkins, Asymmetric Politics: Ideological Republicans and Group Interest Democrats (New York, 2016).

${ }^{16}$ Jill Lepore, These Truths: A History of the United States (New York, 2018), 706.

${ }^{17}$ Ibid., 711.

${ }^{18}$ Ibid., 742-3 (Limbaugh), 713-5 (Jones).

${ }^{19}$ Daniel T. Rodgers, Age of Fracture (Cambridge, MA, 2011); Bruce Schulman, "Daniel Rodgers's (New) Consensus History," Historically Speaking 12, no. 2 (Apr. 2011): 14-5; Matthew D. Lassiter, "Ten Propositions for the New Political History," in Shaped by the State: Toward a New Political History of the Twentieth Century, eds. Brent Cebul, Lily Geismer, and Mason B. Williams (Chicago, 2018), 363-76, here 364. See also Matthew Lassiter, "Political History Beyond the Red-Blue Divide," Journal of American History 98, no. 3 (Dec. 2011): $760-4$.
} 
consistently in the middle of these polar opposites. Even in areas where substantive attitudes have shifted significantly, the public has not exactly been polarizing. Take Americans' changing views on LGBTQ rights, for example: Since the 1970s the percentage of people regarding homosexuality as an "acceptable lifestyle" has steadily increased; the idea that gay Americans deserve civil rights protections at the work place reached near-consensus status long ago. ${ }^{20} \mathrm{~A}$ similar picture emerges in the field of immigration, where public attitudes have either not changed much since the 1990s or, if there has been movement, it has been mostly in a pro-immigration direction. ${ }^{21}$ It would seem that there is a story to be told about Americans steadily coming around on some major issues. Within a narrative that relegates the past to a pre-history of polarization, however, that story hardly receives the attention it may well deserve.

Third, telling the history of recent decades as a story of polarization tends to create a narrative of the American polity in decline. "Polarization" is almost always used as a pejorative term: it is meant to invoke dysfunction, instability, conflict. The terminology thus suggests that the status quo ante against which the polarized decades since the 1970s are measured was one of unity and order. The polarization interpretation, almost by definition, casts the "consensus" of the postwar era in a problematically favorable light, considering that it entailed the exclusion of large parts of society from the seats of power and, most importantly, condemned most African Americans to live in a de facto apartheid state. The implied nostalgia for a supposedly better, pre-polarization era is near-omnipresent in political science scholarship. It shines through even in generally excellent and very much historically sound work, such as Steven Levitsky's and Daniel Ziblatt's investigation of How Democracies Die. In one of the most-noticed books of 2018, these authors provide a convincing dissection of how the pre-1960s "consensus" was based on racial exclusion and depended on a cross-party agreement among white men to leave white supremacy intact. The phase of prolonged dissent began when one party denounced the agreement and started actively supporting change in the direction of a more racially just and equal society. In other words, to a significant degree, the crumbling of the "liberal consensus" was the result of attempts to achieve racial progress; in a similar vein, the polarization of (party) politics since the 1970s has also been structured around questions of gender hierarchy. And yet, even though Levitsky and Ziblatt articulate all this in the most incisive fashion, they still combine their warning against the dangers of polarization with praise for the mid-twentieth-century consensus era that was supposedly characterized by "egalitarianism, civility, sense of freedom." 22

Historians are not immune to these specific effects either. Kruse and Zelizer, for instance, use pejorative terms such as "division," "discord," and "chaos" to characterize developments since the 1970s. They do signal their discomfort with an overly rosy reading of the middle decades of the twentieth century when they speak of the "somewhat forced 'consensus' of the postwar era." ${ }^{23}$ But the exact nature of this consensus is never examined in Fault Lines, and whatever reservations the authors have, they are not enough for them to break out of the structural confines of the polarization narrative.

When it goes unchecked, polarization-induced nostalgia can completely distort the analysis of recent decades. Lamenting the end of a "midcentury era of political consensus," Jill Lepore diagnoses "division, resentment, and malice" as the animating forces in American politics since the late 1960s. In her interpretation, "wrenching polarization" brought "the Republic to the brink of a second civil war" and shaped America's recent past "to the detriment of everyone." But what if it did not? We should be reluctant to embrace a paradigm that seems hardly able to

\footnotetext{
${ }^{20}$ Kruse and Zelizer acknowledge these developments, but still present them within a narrative that emphasizes polarization; see Fault Lines, 272.

${ }^{21}$ McCarty, Polarization, 13-5.

${ }^{22}$ Steven Levitsky and Daniel Ziblatt, How Democracies Die (New York, 2018), 231.

${ }^{23}$ Kruse and Zelizer, Fault Lines, 4.

${ }^{24}$ Lepore, These Truths, 633, 658, 546.
} 
distinguish between the fact that, in a vacuum, unity is good-and the fact that in the reality of American history, consensus politics has often stifled necessary change, and what is usually discussed as polarization has been the prize for very real advancements in racial, gender, and social equality.

As a whole, the polarization prism tends to reproduce current self-descriptions by projecting them onto the past, thus impeding the task of historicizing the prevailing discourses of our era. The lesson here is not, however, to stop engaging with polarization-but to make the concept itself the focal point of historical analysis. We should not content ourselves with accepting the omnipresence of the polarization idea as a mere representation of supposedly unprecedented division, but instead strive to properly historicize the polarization discourse. When did the diagnosis first appear, and what different meanings and connotations has the term acquired over the past several decades? On what empirical basis has the diagnosis been made, howand by whom-has that empirical evidence been constructed and interpreted, and what are the means and channels by which the diagnosis has been popularized? We should investigate the narratives of polarization, their uses and abuses in politics, but also engage in a good deal of self-historicization by examining the ways in which polarization has been theorized in the social and political sciences as well as by historians. Finally, we should place the idea of polarization in the context of other diagnoses of social, cultural, and political fragmentation since the end of the "liberal consensus." This should include an exploration of the motives behind the use of the term and why it has seemed so convincing to so many different people at certain moments. Could it be that much of its attractiveness stems from the fact that it channels perceptions of fundamental change; that it serves as a way to voice widespread insecurities related to the rapid transformation of American society without necessarily assessing blame; that it provides a rhetoric of rapprochement since it does not require agreement as to what is actually ailing America, only that "polarization" is to the detriment of all?

These are just some of the building blocks for a provisional research agenda that aims at historicizing the idea of polarization, its use, and its effects. Polarization is here to stay, at least for the foreseeable future. It is high time for scholars to grapple in earnest with the concept and its larger historiographical implications. Doing so might provide a valuable window into the central conflicts, ideas, and motivations that have defined the most recent past and are very much defining the present.

Thomas Zimmer is assistant professor of history at the University of Freiburg in Germany, where he teaches twentieth-century U.S. and Transatlantic history. His first book, Welt ohne Krankheit. Geschichte der internationalen Gesundheitspolitik 1940-1970 (Wallstein Verlag, 2017), explored the history of global public health after the Second Word War and the American role in international health politics. He is currently writing a history of polarization in the United States since the 1960s, aiming to historicize the idea of polarization; how it has been theorized in the social and political sciences, employed by historians, and used in politics; and how it has shaped the broader political discourse. Pronouns: he/him; Twitter: @tzimmer_history. 